\title{
Spectrum (characteristics) of patients with chronic kidney disease (CKD) with increasing age in a major metropolitan renal service
}

Usman Mahmood ${ }^{1,2,4^{*}}$ (D), Helen G. Healy ${ }^{1,2}$, Adrian Kark ${ }^{1,2}$, Anne Cameron ${ }^{1,2,3}$, Zaimin Wang ${ }^{2,3}$, Rajitha Abeysekera ${ }^{1,2}$ and Wendy E. Hoy ${ }^{2,3}$

\begin{abstract}
Background: Aim of our study is to describe, in people with CKD, the demographic and clinical characteristics and outcomes with increasing age. The prevalence of CKD in Western populations, where longevity is the norm, is about 10-15\%, but how age influence different characteristics of patients with CKD is largely not known.

Methods: One thousand two hundred sixty-five patients enrolled in the CKD.QLD registry at the Royal Brisbane and Women's Hospital were grouped according to age at consent i.e. $<35,35-44,45-54,55-64,65-74,75-84,85+$ years age groups, and were followed till start of renal replacement therapy (RRT), death, discharge or the censor date of September 2015.

Results: Age ranged from 17.6 to 98.5 years with medians of 70.1 and 69.9 years for males and females respectively: $7 \%$ were $<35$ years of age, with the majority $(63 \%)>65$ years old. The leading renal diagnoses changed from genetic real disease (GRD) and glomerulonephritis (GN) in the younger patients to renovascular disease (RVD) and hypertension (HTN) in older patients. With increasing age, there were often multiple renal disease diagnoses, more advanced stages of CKD, greater number of comorbidities, more frequent and more costly hospitalizations, and higher death rates. The rates of initiation of renal replacement therapy (RRT) rose from 4.5 per 100 person years in those age $<35$ years to a maximum of 5.5 per 100 person years in $45-54$ years age group and were lowest, at 0.5 per 100 person years in those $>85$ years. Mortality rates increased by age group from 1.3 to 17.0 per 100 person years in 35-44 year and 85+ year age groups respectively. Rates of hospitalization, length of stay and cost progressively increased from the youngest to eldest groups. Patients with diabetic nephropathy had highest incidence rate of RRT and death. The proportion of patients who lost more than $5 \mathrm{mls} / \mathrm{min} / 1.73 \mathrm{~m}^{2}$ of eGFR during at least 12 months follow up increased from $13.3 \%$ in the youngest age group to $29.2 \%$ in the eldest. (Continued on next page)
\end{abstract}

\footnotetext{
* Correspondence: usman-mahmood@hotmail.com

${ }^{1}$ Kidney Health Services, Metro North Hospital and Health Service, Royal Brisbane \& Women's Hospital, Brisbane, QLD, Australia ${ }^{2}$ NHMRC CKD.CRE \& CKD.QLD, Brisbane, QLD, Australia

Full list of author information is available at the end of the article
} 
(Continued from previous page)

Conclusion: This is the first comprehensive view, with no exclusions, of CKD patients seen in a public renal specialty referral practice, in Australia. The age distribution of patients encompasses the whole of adult life, with a broader range and higher median value than patients receiving RRT. Health status ranged from a single system (renal) disease in young adults through, with advancing age, renal impairment as a component of, or accompanying multisystem diseases, to demands and complexities of support of frail or elderly people approaching end of life. This great spectrum demands a broad understanding and capacity of renal health care providers, and dictates a need for a wider scope of health services provision incorporating multiple models of care.

Keywords: Heterogeneity, Chronic kidney disease, Age distribution, Clinical characteristics, Outcomes, Renal replacement therapy, Death, Progression, Hospitalization, CKD.QLD registry

\section{Background}

Chronic Kidney Disease (CKD) is a significant public health problem worldwide because of the poor outcomes experienced by patients and high associated costs [1-3]. It is the most common chronic disease in Australia with approximately $10 \%$ of adults (1.7 million) affected according to estimates by the Australian Institute of Health and Welfare [4] and a prevalence of $14 \%$ as per the AusDiab study [5]. Control of CKD is confounded by its heterogeneity; of patient demographics, etiology of disease, and number and type of complications and co-morbidities. Patients in whom CKD is not controlled experience excess morbidity and mortality, especially cardiovascular mortality [6-9]. Furthermore the cost of managing these poor health outcomes is high with renal replacement therapy (RRT) for end stage kidney disease (ESKD) alone costing a huge amount of money to health systems [2]. All of the opportunity of controlling CKD, once present, lies with slowing disease progression, preventing complications, especially cardiovascular complications, and preventing ESKD. Early detection, better understanding of disease mechanisms and personalized treatment of the CKD complex are all needed. However, there are paucity of data of the interactions of demographics, etiologies, complications and comorbidities, including their impact on the postulated pathway of a self-perpetuating vicious cycle of fibrosis independent of the initial renal injury [10].

Furthermore, the weight of different components of the complex causal interactions is changing. Elderly people are the fastest growing population group [11] and elderly patients are characterized by different causes of kidney disease and higher co-morbidities than younger age groups [12]. Therapies based on evidence generated in younger age groups may therefore not be applicable to those of an older demographic. Furthermore personalized treatment of CKD in the elderly must be cognizant of likely interacting and coexisting health needs in a cohort who have accumulated deficits in multiple organs requiring further customizing of their bundle of care. Modification of drug selection and dosing is one example [13].
We aim to describe patient, kidney and co-morbid characteristics across age groups in a large and current population of the Chronic Kidney Disease in Queensland (CKD.QLD) cohort. CKD.QLD [14]. CKD.QLD, established in late 2009, is a statewide multidisciplinary research and practice program, conducted through a collaboration of academics and specialists in kidney care in the public health sector in Queensland. CKD.QLD encompasses a CKD registry involving all consenting patients referred to public renal practices (prior to renal replacement therapy RRT) in Queensland, which is the third most populous Australian state/territory. CKD.QLD has identified some important differences between CKD.QLD registry patients (a pre-dialysis population) and those patients who have survived a renal death and are on RRT in Australia. Notably, the CKD.QLD cohort included older people with no gender difference, unlike the male-dominant RRT population, and has a higher percentage of patients with renal vascular disease and a lower percentage with diabetic nephropathy [15].

\section{Methods}

This is a prospective observational cohort study of 1265 participants who were enrolled, with informed consent, in the CKD.QLD registry [15] at the Kidney Health Service, Royal Brisbane and Women's Hospital (Metro North Hospital and Health Service), Queensland Health. Their characteristics were documented at baseline; they were followed longitudinally and, for the purpose of this description of outcomes, censored at commencement of renal replacement therapy (RRT), death, discharge or September 2015.

"Chronic Kidney Disease in Queensland (CKD.QLD) Registry Study" has Royal Brisbane and Women's Hospital Human Research Ethics Committee approval - HREC Reference Number (MNHHS): HREC/15/QRBW/294 as of June 2015 (Previous HREC Reference Number (OHMR): HREC/10/QHC/41 from Nov 2010 to June 2015 University of Queensland Medical Research Ethics Number: 2011000029). 


\section{Participant population}

The study population is a group of 1265 patients managed by a single service provider, the Kidney Health Service (KHS), Metro North Hospital and Health Service (MNHHS), a specialty service in the publicly funded health system. The first participant gave informed consent to join the CKD.QLD cohort in May 2011. Participants were progressively enrolled at clinical consultations at different clinic locations, all under the umbrella of KHS, MNHHS. Patients were grouped according to age at consent into $<35,35-44,45-54,55-64,65-74,75-84$ and $85+$ years.

\section{Inclusion and exclusion criteria}

All adult patients referred to the MNHHS KHS, not on RRT, and able to give informed consent, were offered enrolment in the CKD.QLD Registry. Patients were excluded if pediatric, already on RRT, or unable to give informed consent. Rates of patients declining Registry participation were less than $1 \%$.

\section{Data collection and patient characteristics}

Data were extracted from the clinical records of participants, both electronic and hardcopy, at the time point of consent and throughout the study period. Outcomes were sourced from a combination of these records and organisational datasets, including hospital records for each admission and ANZDATA (http://www.anzdata.org.au) for a comparative population of RRT patients. Data extractions included 1) Demographics - age, gender, weight, height and derived body mass index (BMI) 2) cause/s of chronic kidney disease (clinical diagnosis) as determined by the treating Nephrologist; these causes were grouped into seven categories in both genders i.e. glomerulonephritis (GN), genetic renal disease (GRD), loss of single kidney, diabetic nephropathy (DN), renovascular disease including hypertension, and categories of other and uncertain. We also recorded the number of renal diagnoses in all patients, both males and females. Some participants were accorded more than one cause for CKD by their treating nephrologist. 3) Stage of CKD (1, 2, 3A, 3B, 4 and 5) at the time of consent to the registry 4) The presence of specific clinically diagnosed co-morbidities were recorded: these included coronary artery disease, cerebrovascular disease, hypertension, peripheral vascular disease, diabetes, gout, obstructive sleep apnoea, chronic lung disease and cognitive impairment/dementia 5) Outcomes measured included death, start of RRT (cause specific), hospitalisation including length of stay, causes of specific hospitalisation, and changes in eGFR over the follow-up period.

Stage of CKD was calculated by using CKD-EPI formula for estimated glomerular filtration rate (eGFR) [16]. The outcome of death was recorded as the raw number of patients who died and the incidence of death per 100 person years of follow up was calculated. The outcome of initiation of RRT was recorded as the raw number of patients who started RRT, the incidence of RRT per 100 person years and the primary renal diagnosis in that patient. Rates of hospitalisation per 100 person years and the top 10 causes of hospitalisation were recorded by using diagnosis related group (DRGs) code set. Changes in eGFR were transformed to rate of change of eGFR over 12 months and categorised as progressive if declining by $>5 \mathrm{ml} / \mathrm{min} /$ $1.73 \mathrm{~m}^{2}$, improved if there was gain of $>5 \mathrm{ml} / \mathrm{min} / 1.73 \mathrm{~m}^{2}$ and stable if there was less than $+/-5 \mathrm{ml} / \mathrm{min} / 1.73 \mathrm{~m}^{2}$ of eGFR change over at least 12 months follow up.

\section{Results}

Age, gender, ethnicity and body mass index (BMI)

Age of patients in our cohort ranged from a minimum of 17.7 years to a maximum of 98.5 years. Majority of patients i.e. $63 \%(798 / 1265)$ in our study were over 65 years of age. Gender distribution was similar, 651 males and 614 females. Out of 1265 participants in our study, 804 patients had available data on ethnicity. Vast majority of study population (791/804) was Caucasian (98.3\%). 13/804 (1.6\%) patients were of aboriginal/indigenous descent. Table 1 demonstrates age groups, number of patients in each age group, mean ages, gender and BMI.

Height ranged from $130.5 \mathrm{~cm}$ to $223.6 \mathrm{~cm}$ and weight ranged from $32.2 \mathrm{~kg}$ to $200.9 \mathrm{~kg}$. Median BMI was either in 'overweight' or 'obese' category in all age groups (Table 1)

Table 1 Age, gender distribution and median (IQR) BMI stratified for age groups

\begin{tabular}{lllllll}
\hline Age group (years) & Number $(\mathrm{n})$ & Females $(\mathrm{n})$ & Males $(\mathrm{n})$ & Mean age (years) & Standard deviation $(\mathrm{SD})$ & Median $(\mathrm{IQR}) \mathrm{BMl}\left(\mathrm{kg} / \mathrm{m}^{2}\right)$ \\
\hline$<35$ & 89 & 53 & 36 & 27.4 & 2.3 & $27.7(23.4-32.6)$ \\
$35-44$ & 76 & 38 & 38 & 40.7 & 2.8 & $29.2(25.5-35.6)$ \\
$45-54$ & 122 & 56 & 66 & 50.5 & 2.8 & $29.0(25.5-35.0)$ \\
$55-64$ & 180 & 82 & 98 & 60.5 & 2.8 & $31.6(27.3-38.1)$ \\
$65-74$ & 359 & 163 & 196 & 70.2 & 2.8 & $31.2(27.1-36.0)$ \\
$75-84$ & 341 & 172 & 169 & 80.0 & 2.8 & $28.1(24.8-31.9)$ \\
$85+$ & 98 & 50 & 48 & 87.8 & 2.4 & $26.0(23.4-29.0)$ \\
Total & 1265 & 614 & 651 & 66.2 & 16.5 & $29.2(25.3-34.5)$ \\
\hline
\end{tabular}


but tended to be lowest in the most elderly age group (85+ years). This is consistent with findings from Kramer's "BMI in an incident ESRD population" study [17].

\section{Etiology/primary renal diagnoses and number of renal disease diagnoses}

Overall, renovascular disease (including hypertension) was the most common primary renal diagnosis (38.4\%), reflecting the preponderance $(63 \%>65$ years $)$ of older participants. This contrasts with the ESKD population on RRT in Australia according to ANZDATA, where diabetes continues to be the leading cause [18]. The second leading cause was 'Others' category (19.3\%) which mostly included analgesic nephropathy, nephrolithiasis, reflux nephropathy and lithium related CKD and number of other rare causes. Diabetic nephropathy was the 3rd most common cause of CKD in our study population, with a prevalence of $17.4 \%$. The proportions by primary renal diagnosis differed markedly by age. The main primary renal diagnoses in different age groups are shown in Fig. 1. In the younger age groups ( $<65$ years) glomerulonephritis (GN) and genetic renal disease (GRD) were the most common primary renal diagnoses/etiologies of chronic kidney disease. Diabetic nephropathy had a modal distribution, and progressively increased in prevalence from $6.7 \%$ in the $<35$ to $28.3 \%$ in the 55-64 year age group before declining to $8.1 \%$ in the $85+$ age group. Overall, renovascular disease (including hypertension) progressively increased in prevalence with participant age, reaching a peak of $69.3 \%$ in oldest age group (85+).

The number of renal disease diagnoses per patient ranged from 1 to 4 . In total, $55 \%$ of participants had a single renal diagnosis and $33.7 \%, 9.3 \%$ and $2 \%$ respectively had 2, 3 and 4 primary renal diagnoses. In $<35$ year age group, $74.1 \%$ of patients had a single renal diagnosis (mean number of diagnoses 1.3, SD 0.5) compared to $58.1 \%$ in $85+$ age group (mean number of diagnoses 1.5 , SD 0.7). Elderly patients (85+ age group) tended to have more than one contributing renal diagnoses $(41.8 \%)$ attributed to their CKD compared to $25.8 \%$ in younger CKD patients ( $<35$ year age group). In the intermediate age group (55-64y) 82 patients $(45.5 \%)$ had one primary renal diagnosis whilst 98 patients (54.4\%) had more than one primary renal diagnosis. Fig. 2 shows the number of renal disease diagnoses [1-4] in different age groups.

\section{CKD stage at consent to CKD.QLD registry}

The distribution of CKD stage differed by age. $74.7 \%$ of elderly patients (over 65 years of age) were in later stages of CKD i.e. stage $3 \mathrm{~B}$ to 5 , at the time of enrolment to the CKD.QLD registry. In contrast, $60.3 \%$ of younger patients (under 65 years) had CKD stage 1,2 or $3 \mathrm{~A}$ at the time of consent (Fig. 3).
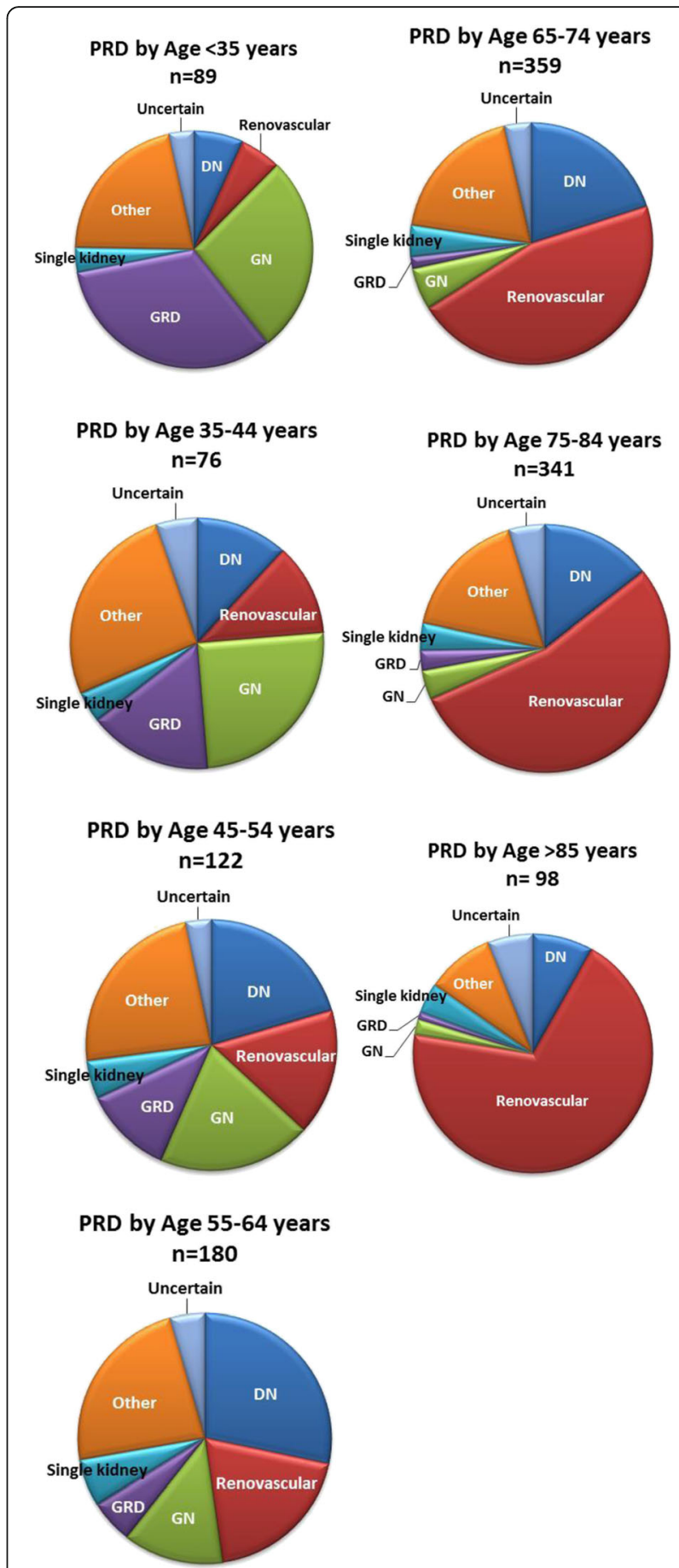

Fig. 1 Primary Renal Diagnosis (PRD) in different age groups

\section{Comorbidities}

Of leading comorbidities, excluding anaemia and dyslipidaemia, 9 were reviewed, with a mean of 0.7 (SD 0.8) in those $<35$ years and mean of 2.9 (SD 1.2) in 85+ age group. All comorbidities were more common in males than females; mean 2.8 (SD 1.7) in males as compared to 2.2 (SD 1.5) in females $(p<0.001)$. Comorbidities 


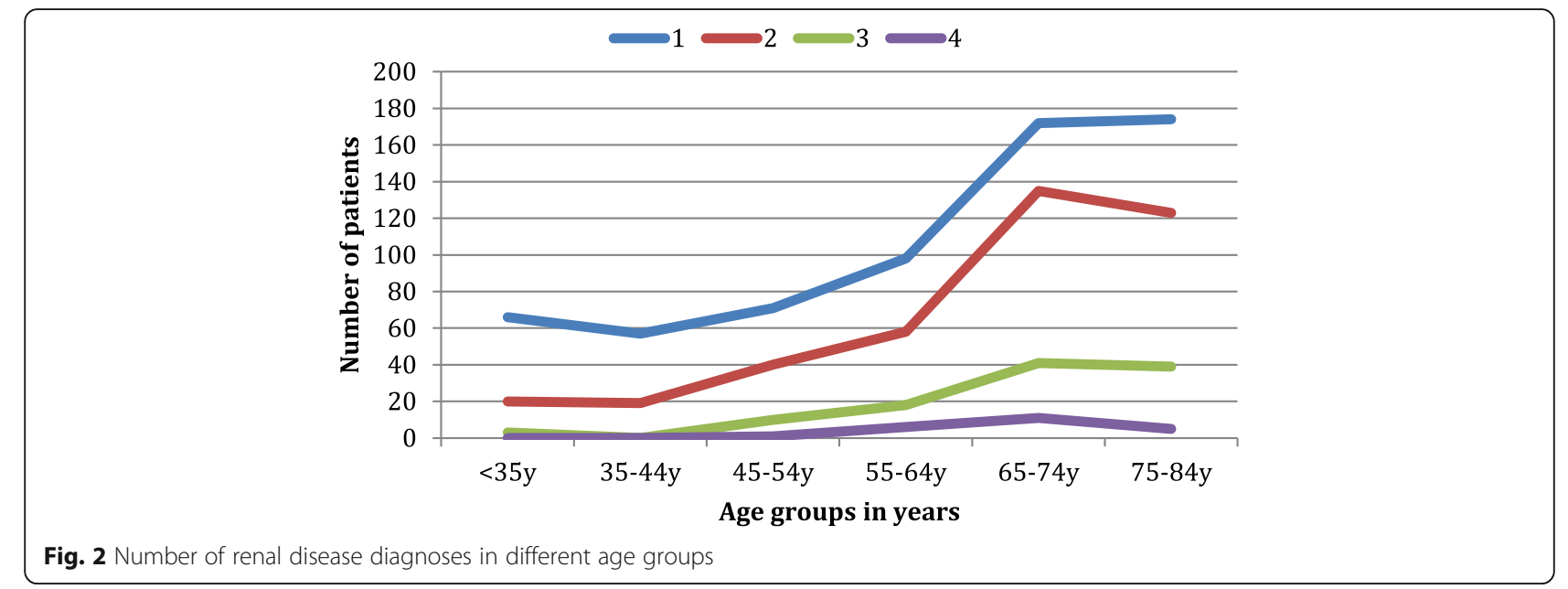

documented include coronary artery disease (CAD), cerebrovascular disease (CVD), hypertension (HTN), peripheral vascular disease (PVD), diabetes mellitus (DM), gout, sleep apnoea, chronic lung disease and cognitive impairment/dementia.

\section{Outcomes}

\section{Start of renal replacement therapy (RRT)}

Eighty-six (6.8\%) patients started RRT during the followup period. Relatively more were male $(n=50)$ than female $(n=36)$. Seventeen patients $(3.5 \%)$ among the cohort of 486 with reno vascular disease started RRT, whilst $79(16.3 \%)$ patients died in the same group over the follow-up period $(\mathrm{p}<0.001)$. Figure 4 shows rates of RRT by age. Rates of RRT increased from 1.8 per 100 person years (35-44 years) to 5.5 per 100 person years (45-54 years) and subsequently fell to the lowest rate of 0.5 per 100 person years in those over 85 years of age.
Cumulative incidence of RRT considering competing risk is shown in Fig. 5.

Similar patterns were observed in both sexes. Patients with diabetic nephropathy had the highest RRT incidence rates (7.8 in males and 5.4 per 100 person years in females) compared to other primary renal diagnoses.

\section{Deaths}

One hundred sixty-nine patients (92 males, 77 females) died during the follow-up period in the study. The incidence of death by age group is shown in Fig. 6 below. Death rates progressively increased from 0 per 100 person years in $<35$ years age group to 17.0 per 100 person years in over $85 \mathrm{~s}$, with similar trends in males and females. Incidence of death (cumulative) considering competing risk is shown in Fig. 7. Patients with diabetic nephropathy had highest incidence rates of death (7.8 in males and 8.0 in females per 100 person years). Annual progression rate (percentage) from CKD stages $2,3,4$ and 5 at the time of

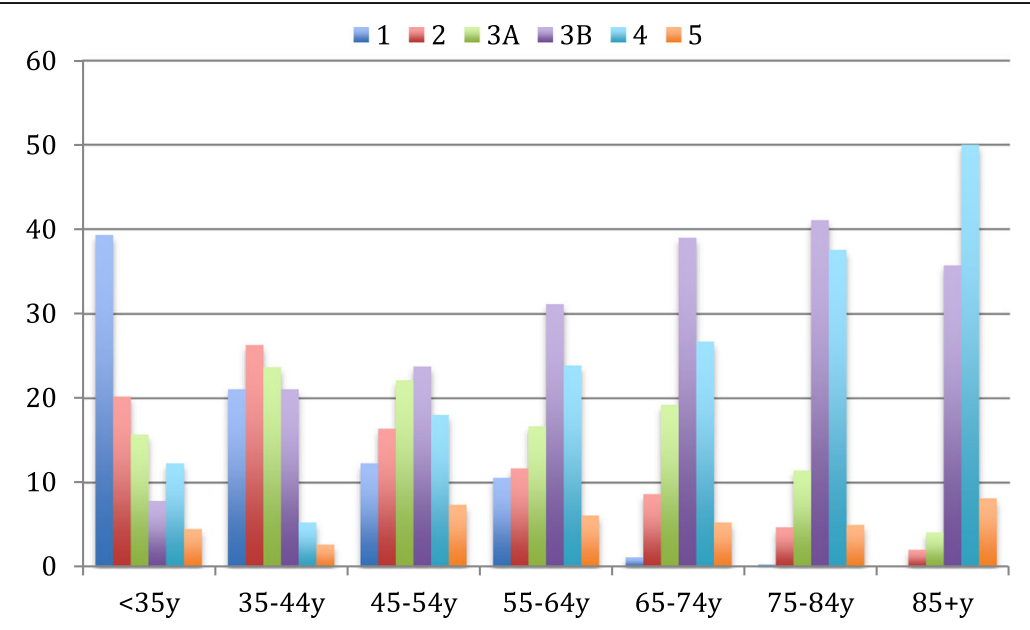

Fig. 3 CKD stage at consent in different age groups ( $y$-axis represents percentage of patients) 


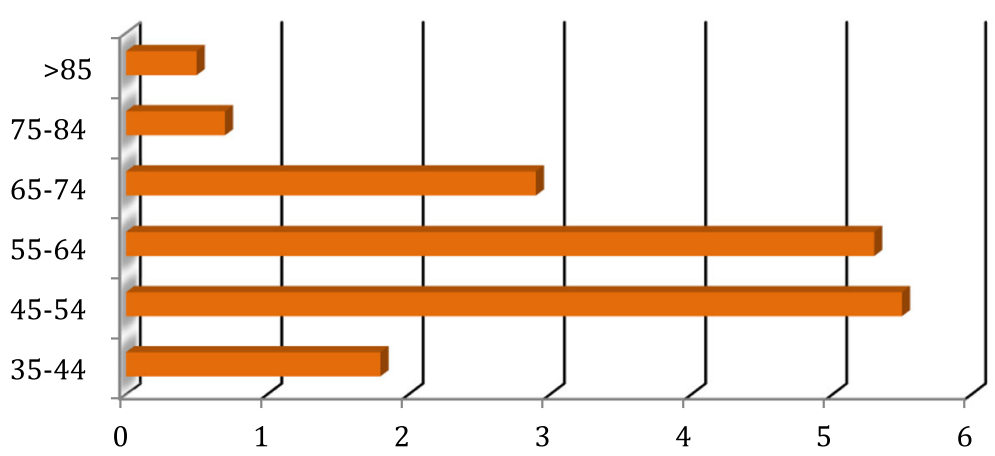

Fig. 4 Incidence (rate) of renal replacement therapy per 100 person years

consent to RRT and death stratified by $<75$ years and $>75$ years age groups is shown in Table 2 below.

\section{Progression (change in eGFR over follow-up)}

In patients in whom eGFR (calculated by CKD EPI equation) was followed for at least one year $(n=905), 19.3 \%$ $(175 / 905)$ had improvement in eGFR (defined by increase of $>5 \mathrm{ml} / \mathrm{min} /$ year) whilst $24.7 \%$ (224/905) experienced significant loss of eGFR (progression) defined by loss of $>5 \mathrm{ml} / \mathrm{min} /$ year $(p=0.006) .66 .6 \%$ of patients under 35 years and $55.4 \%$ of $85+$ years had stable renal function (eGFR changes up to $+/-5 \mathrm{ml} / \mathrm{min}$ /year). Elderly people (85+) were more likely to have progression of CKD $(29.2 \%)$ as compared to $13.3 \%$ of those ages $<35$ yr. Overall, the majority of the cohort $(55.9 \%)$ had stable renal function over a 12-month follow-up.

\section{Hospitalisations}

Five hundred fourteen patients (261 males and 253 females) had at least one hospitalisation to Royal Brisbane \& Women's Hospital during the follow-up period, out of total population of 1150. As shown in Table 3, patients over 65 years of age had the highest number of hospitalisation episodes. There were 394 hospitalisation episodes in those aged 65-74 years, 632 episodes in those between 75 and 84 years and 97 episodes in over 85 years. The rate of hospitalisation per 100 person years increased from 64.2 in patients less than 35 years of age to a peak of 124.6 in $75-84$ year age group.

\section{Discussion}

Australia has excellent available data regarding End Stage Kidney Disease (ESKD) patients on RRT in the form of the ANZDATA registry [19] but there is paucity

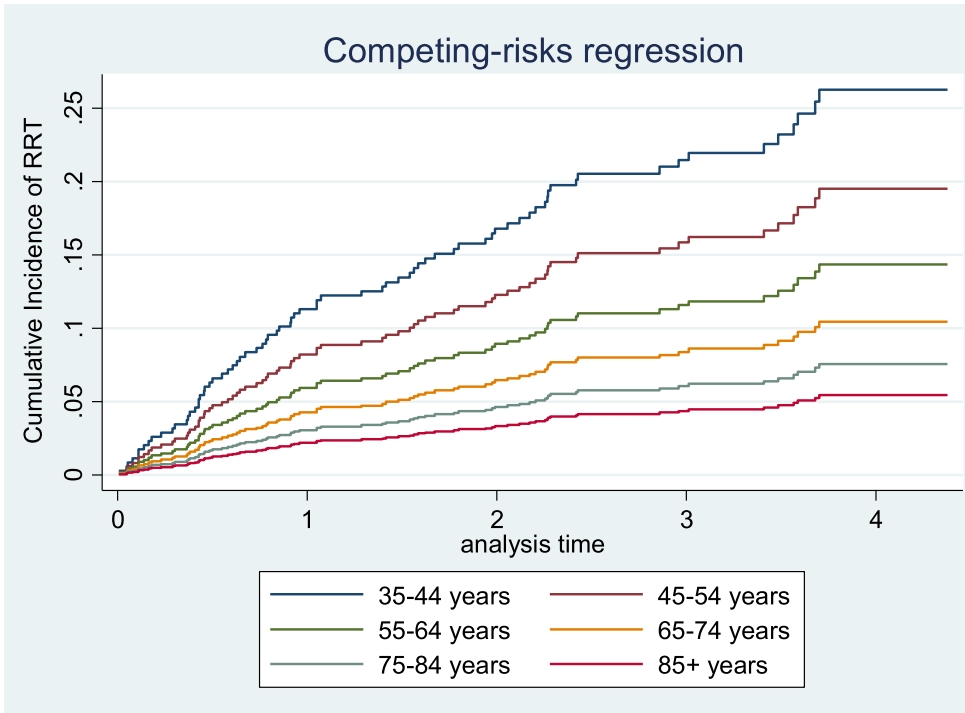

$\mathrm{x}$-axis - analysis time in years

$\mathrm{y}$-axis - probability of renal replacement therapy (RRT)

Fig. 5 Cumulative incidence of renal replacement therapy considering competing risk 


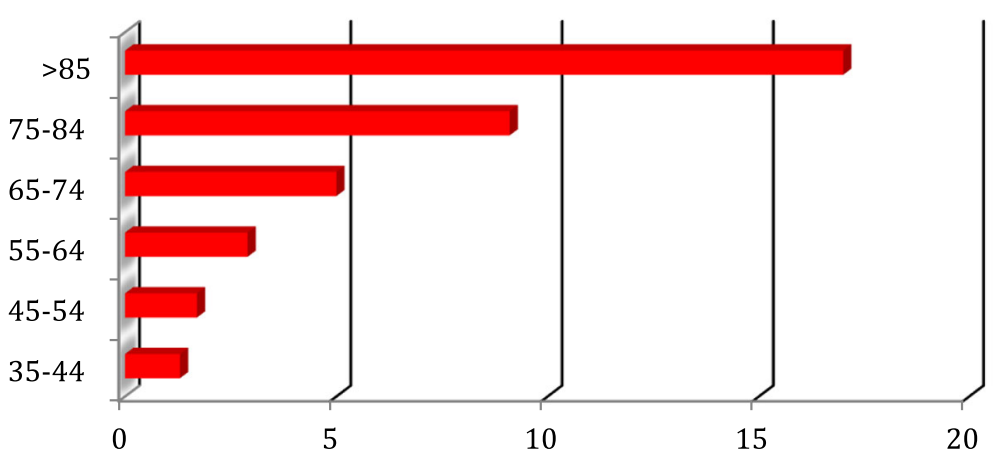

Fig. 6 Incidence (rate) of death per 100 person years

of data regarding earlier stages of CKD before the need for RRT, or those who do not go on to RRT. Our study is one of the few providing opportunities to look at preterminal CKD, through examining patients referred by other health care providers (mostly in primary care) to renal specialty services, across all age groups from young adults through to very elderly. This study population consists of 1265 patients with CKD referred for evaluation and/or management to a single renal specialty service, although with multiple clinics, in a metropolitan setting (Kidney Health Service (KHS), Metro North Hospital and Health Service (MNHHS)), within the publicly funded Queensland Health system.

There were no exclusions in our study based on age or range of eGFR. This contrasts with other published studies of renal specialty-based CKD patients. Other CKD cohort studies like German Chronic Kidney Disease
(GCKD) [20], the Chronic Renal Insufficiency Cohort (CRIC) [21] and the Chronic Kidney Disease Japan Cohort (CKD-JAC) [22] excluded patients over 75 years of age or excluded patients with milder forms of CKD, represented by eGFR over $60 \mathrm{ml} / \mathrm{min} / 1.73 \mathrm{~m}^{2}$ (GCKD, CKD-JAC and CKD-REIN - The French Chronic Kidney Disease Renal Epidemiology and Information Network cohort study [23]) or over $45 \mathrm{ml} / \mathrm{min} / 1.73 \mathrm{~m}^{2}$ (CanPREDDICT [24] Cohort profile: Canadian study of prediction of death, dialysis and interim cardiovascular events). The International Network of CKD cohort studies (iNET-CKD) has recently been established to promote research and conduct observational studies of appropriate sample size, follow-up and defined objectives including patient level outcomes. This will facilitate comparative research and identify the differences (genetic, behavioural and health services factors) associated with the course of CKD [25].

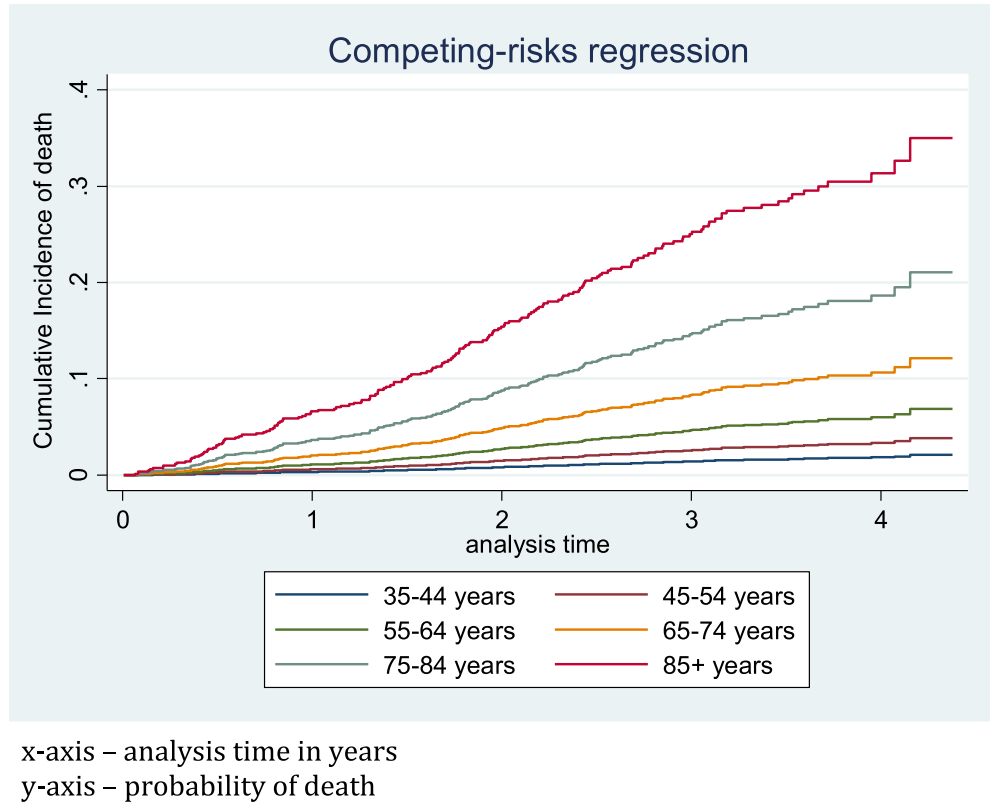

Fig. 7 Cumulative incidence of death considering competing risk 
Table 2 Annual progression rates stratified by age

\begin{tabular}{|c|c|c|c|c|c|c|}
\hline \multirow[b]{2}{*}{$\begin{array}{l}\text { CKD stage at } \\
\text { consent }\end{array}$} & \multirow[b]{2}{*}{$\begin{array}{l}\text { Number of } \\
\text { patients }\end{array}$} & \multirow[b]{2}{*}{$\begin{array}{l}\text { Follow-up } \\
\text { years }\end{array}$} & \multicolumn{2}{|l|}{ Progress to RRT } & \multicolumn{2}{|l|}{ Progress to death } \\
\hline & & & $\begin{array}{l}\text { Total number of patients } \\
\text { progressing to RRT }\end{array}$ & $\begin{array}{l}\text { Annual progression } \\
\text { rate }(\%)^{\mathrm{a}}\end{array}$ & $\begin{array}{l}\text { Total number of } \\
\text { patients' death }\end{array}$ & $\begin{array}{l}\text { Annual progression } \\
\text { rate }(\%)^{\mathrm{a}}\end{array}$ \\
\hline \multicolumn{7}{|c|}{ Patients aged $<75$ years } \\
\hline CKD 2 & 110 & 279.5 & 1 & 0.4 & 2 & 0.72 \\
\hline CKD 3 & 406 & 1087.9 & 8 & 0.7 & 28 & 2.57 \\
\hline CKD 4 & 176 & 396.7 & 39 & 9.8 & 30 & 7.56 \\
\hline CKD 5 & 45 & 47.9 & 31 & 64.7 & 3 & 6.26 \\
\hline \multicolumn{7}{|c|}{ Patients aged $>/=75$ years } \\
\hline CKD 2 & 18 & 38.4 & 0 & 0.0 & 4 & 10.4 \\
\hline CKD 3 & 218 & 537.3 & 1 & 0.2 & 29 & 5.4 \\
\hline CKD 4 & 177 & 391.5 & 3 & 0.8 & 58 & 14.8 \\
\hline CKD 5 & 25 & 28.3 & 3 & 10.6 & 14 & 49.5 \\
\hline
\end{tabular}

Notes: Annual rate of progression (per 100 person years) $=$ (total patients (RRT or death) $/$ follow-up years) ${ }^{\text {a }} 100$

Additional strengths of this study include the diversity of subjects, representing the very multicultural mix of the Australian population. In contrast, the GCKD [20] cohort had 100\% Caucasian patients, CanPREDDICT [24] had a low prevalence of non-Caucasian individuals and the CKD-JAC cohort [22] had only Japanese patients who have lower cardiovascular disease prevalence. Our cohort also had uniform access to health resources and shared practice protocols within the entire Queensland public health service. Moreover, our study links participant demographics, clinical characteristics and laboratory data to clinically significant outcomes, while some studies e.g. Alberta Kidney Disease Network (AKDN) [26] rely on only laboratory data to describe a study population. The comprehensive nature of our data provides a basis for international comparison and crossvalidation of findings.

In this study we found significant heterogeneity by age in terms of CKD stage, etiology and number of renal disease diagnosis, comorbidities as well as outcomes of renal replacement therapy, death, rate of progression of CKD and of hospitalizations. Being sourced from specialty nephrology practices, the majority of patients $(66.8 \%)$ were in more advanced stages of CKD (stage 3B, 4 and 5) at entry into the CKD.QLD cohort. However, the level of kidney dysfunction at the time of entry was dependent on age. Younger patients entered at earlier stages of CKD, with three quarters (75.2\%) younger than 65 years in either Stage 1 or 2 . This contrasts with only $24.7 \%$ of patients over 65 years entering at stage 1 or 2 . This could represent variability in referrers practice. $63 \%$ of our patients were $\geq 65$ years old, themselves a heterogeneous population, and $34.7 \%$ were $\geq 75$ years old at consent. Better understanding of these individuals is needed, so efforts can be made to slow their disease progression and reduce the burden of ESKD and non-renal complications, because specific therapies to target CKD are very limited as of today, and the elderly are the fastest growing population demographic.

Not surprisingly the prevalence of vascular disease, including renovascular disease, increased from younger to elderly age groups. It was the most common attributable diagnosis in the majority of our patients (38.4\%). Interestingly, diabetic nephropathy contributed to only $17.4 \%$ of

Table 3 Hospitalizations in all age groups (poisson regression used to test significance between rates of hospitalizations in different age groups)

\begin{tabular}{llllll}
\hline Age group & Follow-up years & No. of hospitalizations & $\begin{array}{l}\text { Rate of hospitalization } \\
\text { per 100 person years }\end{array}$ & Incidence rate ratio & $p$ value \\
\hline$<35 y$ & 151 & 97 & 64.2 & 1.0 & 0.9 \\
$35-44 y$ & 135.6 & 79 & 58.2 & 1.7 & $<0.001$ \\
$45-54 y$ & 177.0 & 171 & 96.6 & 1.8 & $<0.001$ \\
$55-64 y$ & 252.9 & 262 & 103.6 & 1.3 & $<0.001$ \\
$65-74 y$ & 523.3 & 394 & 75.3 & 1.2 & $<0.001$ \\
$75-84 y$ & 507.2 & 632 & 124.6 & 1.6 & $<0.001$ \\
$85+y$ & 108.7 & 97 & 89.2 & & $<0.001$ \\
Total & 1856.1 & 1732 & 93.3 & & \\
\hline
\end{tabular}


CKD in our cohort in comparison to much higher prevalence in other studies [27] and it varied with age. Older participants tended to have more than one primary renal diagnosis but a significant minority of younger participants also had multiple renal disease diagnoses. The elderly cohort also had a greater burden of co-morbid diseases, which they had presumably accumulated over the course of their lives or might have been facilitated or accelerated by CKD.

The renal function of the majority (55.9\%) of participants did not deteriorate over the study interval. Whilst this may represent successful models of care, other explanations include a more benign natural history of CKD than expected: it is noteworthy that these data align with the results of CanPREDICCT study [24]. However CKD did progress in a subgroup. This has implications for CKD prognostication to target those who are more likely to progress.

Not unexpectedly, participants in the older age groups have higher incidence of death and lower incidence of RRT, either dialysis or transplantation. The lower rates of RRT may indicate increasing provision of renal supportive/ conservative care as an alternative choice to RRT in those elderly frail patients with multiple medical co-morbidities. Older patients also tended to have more hospitalizations with longer length of stay and utilized more health resources as opposed to younger patients. Tonelli et al. [28] recently demonstrated that comorbidity in CKD patients is an important driver of adverse clinical and economic consequences.

Our study has some limitations. It is a single center study although patients are drawn from multiple hospital and community clinics. As only referred and consented patients with CKD are included in the CKD.QLD registry, therefore, we are unable to generalize our findings to the CKD patients being managed by primary care physicians with no specialist nephrology input. There may be a referral bias as elderly patients with renal impairment are less likely to be referred to specialist renal services than their younger counterparts. Furthermore there are some uncertainties in the etiology of CKD as many physicians made the diagnoses without biopsy confirmation.

\section{Conclusion}

Renovascular disease is the most prevalent attributable cause of CKD overall, reflecting its dominance in the fastest growing elderly (over mean age of 65 years) demographic. Within this population, there is heterogeneity by age in the characteristics and outcomes of CKD. These results support a health provider response that is personalised to the patient and the patient's health profile. Clearly clinical care needs to be tailored to these facts. Our study contributes to the evidence base for research purposes and also to guide policy development and delivery of health care. It forms a basis for further research that personalized care delivers better health outcomes to people with CKD.

\section{Acknowledgements}

The NHMRC CKD Centre of Research Excellence and Chronic Kidney Disease in Queensland Research Collaboratives' (CKD.QLD) (http://www.ckdqld.org) Kidney Health Service, Metro North Hospital and Health Service (KHS MNHHS), Queensland Health

We thank all of the patients who are participating in the CKD.QLD Registry Study

\section{Funding}

Funding for the establishment of CKD.QLD was provided by Prof W.E. Hoys' NHMRC Australian Fellowship (\#5110810), the Colonial Foundation (Melbourne, Australia), AMGEN Australia, Roche, Shire, Janssen and Queensland Health; with current funding provided by the NHMRC CKD Centre of Research Excellence (\#1079502), Queensland Health and AMGEN Australia. Funding body had no role in the design of the study and collection, analysis, and interpretation of data and in writing the manuscript.

\section{Availability of data and materials}

The datasets used and/or analysed during the current study are available from the corresponding author on reasonable request.

\section{Authors' contributions}

First author (UM) was responsible for majority of the work including study design, interpretation of data and manuscript writing. ZW was our biostatistician and helped with data analysis. $\mathrm{WH}, \mathrm{AC}, \mathrm{HH}, \mathrm{AK}$ and RA contributed to the overall study design, manuscript writing and proof reading. All authors read and approved the final manuscript.

\section{Ethics approval and consent to participate}

"Chronic Kidney Disease in Queensland (CKD.QLD) Registry Study" has Royal Brisbane and Women's Hospital Human Research Ethics Committee approval HREC Reference Number (MNHHS): HREC/15/QRBW/294 as of June 2015 (Previous HREC Reference Number (OHMR): HREC/10/QHC/41 from Nov 2010 to June 2015 University of Queensland Medical Research Ethics Number: 2011000029). All participants were adults and gave written informed consent to participate in the study.

\section{Consent for publication}

"Not Applicable"

\section{Competing interests}

The authors declare that they have no competing interests.

\section{Publisher's Note}

Springer Nature remains neutral with regard to jurisdictional claims in published maps and institutional affiliations.

\section{Author details}

${ }^{1}$ Kidney Health Services, Metro North Hospital and Health Service, Royal Brisbane \& Women's Hospital, Brisbane, QLD, Australia. ${ }^{2}$ NHMRC CKD.CRE \& CKD.QLD, Brisbane, QLD, Australia. ${ }^{3}$ Centre for Chronic Disease, University of Queensland, Brisbane, Australia. ${ }^{4}$ Toowoomba Hospital, Toowoomba, QLD, Australia.

Received: 12 March 2017 Accepted: 7 December 2017

Published online: 28 December 2017

\section{References}

1. Jha V, Garcia-Garcia G, Iseki K, Li Z, Naicker S, Plattner B, et al. Chronic kidney disease: global dimension and perspectives. Lancet (London, England). 2013;382(9888):260-72.

2. Lozano R, Naghavi M, Foreman K, Lim S, Shibuya K, Aboyans V, et al. Global and regional mortality from 235 causes of death for 20 age groups in 1990 and 2010: a systematic analysis for the global burden of disease study 2010. Lancet (London, England). 2012;380(9859):2095-128. 
3. Cass ACS, Gallagher M, Howard K, Jones A, McDonald S, et al. The economic impact of end-stage kidney disease in Australia: Projections to 2020 Melbourne: Kidney Health Australia; 2010.

4. Cardiovascular disease, diabetes and chronic kidney disease: Australian facts: prevalence and incidence. Cardiovascular, diabetes and chronic kidney disease series no. 2. Cat. no. CDK 2. Canberra: AlHW; 2014.

5. Chadban SJ, Briganti EM, Kerr PG, Dunstan DW, Welborn TA, Zimmet PZ, et al. Prevalence of kidney damage in Australian adults: the AusDiab kidney study. J Am Soc Nephrol. 2003;14(7 Suppl 2):S131-8.

6. Tonelli M, Wiebe N, Culleton B, House A, Rabbat C, Fok M, et al. Chronic kidney disease and mortality risk: a systematic review. J Am Soc Nephrol. 2006;17(7):2034-47.

7. Foley RN, Parfrey PS, Sarnak MJ. Clinical epidemiology of cardiovascular disease in chronic renal disease. Am J Kidney Dis. 1998;32(5 Suppl 3):S112-9.

8. Weiner DE, Tighiouart H, Amin MG, Stark PC, MacLeod B, Griffith JL, et al. Chronic kidney disease as a risk factor for cardiovascular disease and allcause mortality: a pooled analysis of community-based studies. J Am Soc Nephrol. 2004;15(5):1307-15.

9. Go AS, Chertow GM, Fan D, McCulloch CE, Hsu CY. Chronic kidney disease and the risks of death, cardiovascular events, and hospitalization. N Engl J Med. 2004;351(13):1296-305.

10. Fogo $A B$. Mechanisms of progression of chronic kidney disease. Pediatr Nephrol. 2007;22(12):2011-22

11. Australian Bureau of Statistics. 2014. http://www.abs.gov.au/ausstats/abs@. nsf/lookup/3101.0Media\%20Release1Jun\%202016.

12. Lin MY, Chiu YW, Lee CH, HY Y, Chen HC, MT W, et al. Factors associated with CKD in the elderly and nonelderly population. Clin J Am Soc Nephrol. 2013;8(1):33-40

13. Turnheim K. When drug therapy gets old: pharmacokinetics and pharmacodynamics in the elderly. Exp Gerontol. 2003;38(8):843-53.

14. Venuthurupalli SK, Hoy WE, Healy HG, Salisbury A, Fassett RG. CKD.QLD: chronic kidney disease surveillance and research in Queensland, Australia. Nephrol Dial Transplant. 2012;27(Suppl 3:iii):139-45.

15. Radhakrishnan J, Remuzzi G, Saran R, Williams DE, Rios-Burrows N, Powe N, et al. Taming the chronic kidney disease epidemic: a global view of surveillance efforts. Kidney Int. 2014;86(2):246-50.

16. Levey AS, Stevens LA, Schmid CH, Zhang YL, Castro AF, 3rd, Feldman HI, et al. A new equation to estimate glomerular filtration rate. Ann Intern Med 2009;150(9):604-612.

17. Kramer HJ, Saranathan A, Luke A, Durazo-Arvizu RA, Guichan C, Hou S, et al. Increasing body mass index and obesity in the incident ESRD population. Nephrol Dial Transplant. 2006;17(5):1453-9.

18. ANZDATA Registry. 38th Report. Chapter 1: incidence of end stage kidney disease. Adelaide: Australia and New Zealand Dsialysis and Transplant Registry; 2016. p. 2016

19. McDonald SP. Australia and New Zealand dialysis and transplant registry. Kidney Int Suppl (2011). 2015;5(1):39-44.

20. Titze S, Schmid M, Kottgen A, Busch M, Floege J, Wanner C, et al. Disease burden and risk profile in referred patients with moderate chronic kidney disease: composition of the German chronic kidney disease (GCKD) cohort Nephrol Dial Transplant. 2015;30(3):441-51.

21. Lash JP, Go AS, Appel LJ, He J, Ojo A, Rahman M, et al. Chronic renal insufficiency cohort (CRIC) study: baseline characteristics and associations with kidney function. Nephrol Dial Transplant. 2009;4(8):1302-11.

22. Imai E, Matsuo S, Makino H, Watanabe T, Akizawa T, Nitta K, et al. Chronic kidney disease Japan cohort (CKD-JAC) study: design and methods. Hypertens Res. 2008;31(6):1101-7.

23. Stengel B, Combe C, Jacquelinet C, Briancon S, Fouque D, Laville M, et al. The French chronic kidney disease-renal epidemiology and information network (CKD-REIN) cohort study. Nephrol Dial Transplant. 2014;29(8):1500-7.

24. Levin A, Rigatto C, Brendan B, Madore F, Muirhead N, Holmes D, et al. Cohort profile: Canadian study of prediction of death, dialysis and interim cardiovascular events (CanPREDDICT). BMC Nephrol. 2013;14:121.

25. Dienemann T, Fujii N, Orlandi P, Nessel L, Furth SL, Hoy WE, et al. International network of chronic kidney disease cohort studies (iNET-CKD): a global network of chronic kidney disease cohorts. BMC Nephrol. 2016;17(1):121.

26. Hemmelgarn BR, Clement F, Manns BJ, Klarenbach S, James MT, Ravani P, et al. Overview of the Alberta kidney disease network. BMC Nephrol. 2009;10:30.

27. Collins AJ, Foley RN, Chavers B, Gilbertson D, Herzog C, Johansen K, et al. United States Renal Data System 2011 Annual Data Report: Atlas of chronic kidney disease \& end-stage renal disease in the United States. Am J Kidney Dis. 2012;59(1 Suppl 1):A7, e1-420.

28. Tonelli M, Wiebe N, Guthrie B, James MT, Quan H, Fortin M, et al. Comorbidity as a driver of adverse outcomes in people with chronic kidney disease. Kidney Int. 2015;88(4):859-66.

\section{Submit your next manuscript to BioMed Central and we will help you at every step:}

- We accept pre-submission inquiries

- Our selector tool helps you to find the most relevant journal

- We provide round the clock customer support

- Convenient online submission

- Thorough peer review

- Inclusion in PubMed and all major indexing services

- Maximum visibility for your research

Submit your manuscript at www.biomedcentral.com/submit
Biomed Central 